\title{
Editor Note
}

\section{Reza Tahergorabi ${ }^{*}$}

Assistant Research Professor, Department of Family and Consumer Sciences, Food and Nutritional Sciences, North Carolina A\&T State University, USA

${ }^{*}$ Corresponding author: Dr. Reza Tahergorabi, Assistant Research Professor, Department of Family and Consumer Sciences, Food and Nutritional Sciences, North Carolina A\&T State University, USA, Tel: 336-285-4865; E-mail: rtahergo@ncat.edu

Received date: March 28, 2017; Accepted date: March 29, 2017; Published date: March 30, 2017

Copyright: $\odot 2017$ Tahergorabi R. This is an open-access article distributed under the terms of the Creative Commons Attribution License, which permits unrestricted use, distribution, and reproduction in any medium, provided the original author and source are credited.

\section{Editor Note}

Malnutrition or nutritional disorders are the dark side of unequal socioeconomic growth in the world. Generally, the disorder is defined by the insufficient intake of food and certain nutrients or inability of the body to absorb and use nutrients, which ultimately drags the sufferer towards death. Most of the underdeveloped countries are the victim of such disorder, especially; sub-Sahara African countries are the predominant sufferer from malnutrition. Even in India, more than one million case of malnutrition has been reported [1]. In African perspective, several evolutionary changes have been found to act among the sufferers of malnutrition; 'Lactase Persistence' is the most notable among them [2]. Large scale helps in the form of medicinal support and food relief has been initiated by World Health Organization (WHO) and United Nations Educational, Scientific and Cultural Organization (UNESCO). Though, conclusive abolishment of malnutrition is still an unachieved goal in human civilization. To highlight the timely information on nutritional disorder, the Journal of Nutritional Disorders \& Therapy is providing a platform for communication.

The Journal of Nutritional Disorders \& Therapy is a peer-reviewed Journal, whose scope encompasses a variety of nutrition and health related topics such as: physical fitness, obesity, anorexia, dietary intake etc. In the current issue of the Journal of Nutritional Disorders \& Therapy some interesting findings have been presented, which can be implemented in global healthcare and disease prevention.

Here are the brief highlights of these publications in the Journal of Nutritional Disorders \& Therapy:

Since the second half of 2007, the government of Xinjiang, China implemented a strategy for the management of iodine deficiency disorders (IDD) involving the distribution of iodized salt among the poor in southern Xinjiang. The effect of iodized salt on prevention of IDD was evaluated twice, i.e., 2009 and 2014. Cheng et al. [3], summarized the results of this initiative in Akto County, Xinjiang, China in this study. It was observed that, the median of iodized salt intake was $32.8 \mathrm{mg} / \mathrm{kg}$ in 2004. Rate of goiter in children was estimated to be $10.0 \%$ by B-ultrasound, and $22.0 \%$ by palpation, with a coincidence rate of $66.8 \%$. Compared to 2009, significant improvements were observed in $2014(\mathrm{P}<0.05)$ with respect to the goiter rate in children and urine iodine levels.

Lead in the blood is derived from foods contaminated with Lead, and sometimes from maternal bones which store Lead over long durations. Lead is able to permeate the placenta therefore, accumulation of Lead results in impaired fetal development. Further, individuals exposed to Lead are susceptible to iron deficiency; it is known that iron deficiency can lead to higher Lead content in subjects exposed to Lead. It has long been known that, consumption of kaolin (white clay) leads to Lead accumulation, and that the kaolin-based
Lead can permeate the fetus. Bonglaisin et al. [4], determined the levels of Lead in the cord blood of women consuming kaolin. The authors observed that, Lead does not enter the cord blood when low levels of kaolin are consumed. Further, the authors observed that Lead stored in the bones of the habitual kaolin consumers is released into the blood stream which permeates the cord blood, rendering the fetus and mother vulnerable to lead toxicity.

Geophagy is reported to increase the exposure to Lead, which might then influence the absorption and assimilation of Iron and Iodine. In order to investigate these complex metal-metal interactions, Bonglaisin et al. [5], fed Lead-contaminated kaolin pellets to 12 week-old female albino rats $(n=80)$. In response to the introduction of Kaolin in iodine sufficient diet, the authors observed decreased thyroid iodine content, increased urinary iodine excretion, increased thyroid volume, and normal iodine absorption. Thus, kaolin consumption is related to iodine assimilation, and not iodine absorption in albino rats. Further, the hemoglobin concentrations in kaolin-fed rats were significantly lower than those in control rats, as kaolin inhibits absorption of iron.

Stunting refers to the impaired growth and development of children resulting from poor nutrition or recurrent infection. Children are referred to as stunted if their height-for-age (HAZ) is below two standard deviations (SDs) from the median of the WHO Child Growth Standards. Globally, one in four under-5 years of age is stunted; $80 \%$ of these children are concentrated in just 14 countries spread across Asia and Africa. Shine et al. [6], studied the prevalence of stunting among 6 to 59 month old children in the Korahay Zone, Ethiopia. Towards this, a cross-sectional study was conducted in the pastoral community of the Korahay Zone $(n=770)$. The authors identified that, in this community, the prevalence of stunting was high (31.9\%); a fact which was attributed to the lack of education among mothers, unsafe water supply, lack of toilet facilities, and not feeding the baby first milk. Therefore, educating mothers on feeding practices and proper sanitation are important for countering stunting.

Of all the strategies for management of diabetes, diet is the most explored one. Telfairia occidentalis is a commonly cultivated plant, which is reported to have anti-hyperglycemic properties. It is sometimes consumed along with Citrulus colocynthis seeds which have insulin mimetic properties. Etoundi Omgba et al. [7], studied the effects of dietary supplementation with Telfairia occidentalis leaves along with Citrulus colocynthis seeds on blood sugar and body weight in Wistar rats placed on a carbohydrate-rich diet. The rats were divided into three test groups: (1) 10\% Telfairia occidentalis leaves, (2) $10 \% C$. colocynthis and (3) 5\% T. occidentalis leaves plus 5\% C. colocynthis. Glibenclamide $(0.03 \mathrm{mg} / \mathrm{kg}$ b.w) treated rats were used as positive control. The authors observed that the T. occidentalis $+C$. colocynthis combination was successful at controlling hyperglycemia and maintaining glucose tolerance; therefore, this combinatorial therapy might be recommended for diabetes management in the long run. 
Page 2 of 2

Hypoalbuminemia is commonly encountered in critically ill patients; it is caused when the serum albumin concentration is $\leq 30 \mathrm{~g} / \mathrm{l}$. Albumin is the most prominent protein in the blood plasma and it has remarkably diverse properties such as buffering properties, antioxidant properties, and protein/ion/hormone binding and transport functions. Therefore, lowering of serum albumin levels poses a variety of challenges to perioperative anesthesia [8], present a complicated case of postoperative extubation in a 62-year-old patient having hypoalbuminemia. The patient had been diagnosed with hypoproteinemia, intestinal tuberculosis, and edema 3 years prior. During the administration of anesthesia, the authors encountered some physiological changes in hypoproteinemia. In this article, the authors have provided some guides for the anesthesia management in patients with hypoproteinemia.

Diabetic foot ulcer is a complication of diabetes characterized by improper wound healing. These ulcers are susceptible to infections, and their exudate contains protein-rich lymph which serves as an incubator for microbes. Pan et al. [9], present the case report of a 48year-old man having a 4-year-old history of type 2 diabetes. The patient developed an ulcer $(3 \mathrm{~cm})$ deep into the phalanx on the big toe of his right foot, which later developed multi-drug-resistant Enterobacter cloacae infection. The authors performed wound debridement along with intravenous immunoglobulin administration and Vacuum Sealing Drainage (VSD), which entails placing an open pore-based dressing in the wound cavity, and exposing it to controlled sub-atmospheric pressure; no antibiotic was administered. This strategy resulted in reduction in the size of the ulcer. Antibioticsusceptible Staphylococcus aureus was observed in the wound, a few weeks later, which was managed by antibiotics. Patient recovery was achieved by following this treatment regimen.

At the end, it is expected that such research works may yield diversified avenues of exploration considering different conditions associated with nutritional disorders and therapy.

\section{References}

1. https://g.co/healthpdf/malnutrition_en_IN.pdf

2. Sahi T (1994) Hypolactasia and Lactase Persistence Historical Review and the Terminology. Scandinavian J Gastroenterol 29: 1-6.

3. Cheng W, Juan W, Zhong W, Wei-Wei M, Rong-Xiang X, et al. (2017) Research of Iodine Nutrition Levels in Akto County, Xinjiang, China from 2009 to 2014. J Nutr Disorders Ther 7: 203.

4. Bonglaisin JN, Chelea M, Tsafack TJJ, Lantum DN, Djiele PN, et al. (2017) Assessment of Haemoglobin Status and Transplacental Transport of Lead and Calcium During Geophagy. J Nutr Disorders Ther 7: 204.

5. Bonglaisin JN, Tsafack TJJ, Chelea M, Djiele PN, Mbofung CMF, et al. (2017) Effects of Geophagy on Hemoglobin Level and Iodine Absorption / Assimilation in Albino Rats. J Nutr Disorders Ther 7: 211.

6. Shine S, Tadesse F, Shiferaw Z, Mideksa L, Seifu W (2017) Prevalence and Associated Factors of Stunting among 6-59 Months Children in Pastoral Community of Korahay Zone, Somali Regional State, Ethiopia 2016. J Nutr Disorders Ther 7: 208.

7. Etoundi Omgba BC, Palla Nyamena CL, Manz Koulea CJ, Gouadoa I (2017) Effect of Combined Dietary Supplementation of Telfairia Occidentalis Leaves and Citrulus Colocynthis Seeds on Fasting Glycemia, Glucose Tolerance and Body Weight in Wistar Rats. J Nutr Disorders Ther 7: 209.

8. Cong P, Zhang H, Zhou Y, Xia B, Wang Q (2017) Difficult Postoperative Extubation in a Patient with Hypoproteinemia: A Case Report. J Nutr Disorders Ther 7: 207

9. Pan X, Wu X, Jin X, Xiang S, Su C (2017) Vacuum Sealing Drainage Treatment of Multi-drug-Resistant Enterobacter Cloacae Wound Infection in a Diabetic Patient: A Case Report and Review of the Literature. J Nutr Disorders Ther 7: 210 